\title{
Strategic maintenance technique selection using combined quality function deployment, the analytic hierarchy process and the benefit of doubt approach
}

\author{
Rahul Baidya ${ }^{1}$ Prasanta Kumar Dey ${ }^{1} \cdot$ Sadhan Kumar Ghosh ${ }^{1}$. \\ Konstantinos Petridis ${ }^{2}$
}

Received: 14 April 2016 / Accepted: 25 September 2016 / Published online: 17 October 2016

(C) The Author(s) 2016. This article is published with open access at Springerlink.com

\begin{abstract}
The business performance of manufacturing organizations depends on the reliability and productivity of equipment, machineries and entire manufacturing system. Therefore, the main role of maintenance and production managers is to keep manufacturing system always up by adopting most appropriate maintenance methods. There are alternative maintenance techniques for each machine, the selection of which depend on multiple factors. The contemporary approaches to maintenance technique selection emphasize on operational needs and economic factors only. As the reliability of production systems is the strategic intent of manufacturing organizations, maintenance technique selection must consider strategic factors of the concerned organization along with operational and economic criteria. The main aim of this research is to develop a method for selecting the most appropriate maintenance technique for manufacturing industry with the consideration of strategic, planning and operational criteria through involvement of relevant stakeholders. The proposed method combines quality function deployment (QFD), the analytic hierarchy process (AHP) and the benefit of doubt (BoD) approach. QFD links strategic intents of the organizations with the planning and operational needs, the AHP helps in prioritizing the criteria for selection and ranking the alternative maintenance techniques, and the $\mathrm{BoD}$ approach facilitates analysing robustness of the method through sensitivity
\end{abstract}

Prasanta Kumar Dey

p.k.dey@aston.ac.uk

1 Department of Mechanical Engineering, Jadavpur University, 188 Raja Subodh Chandra Mullick Road, Jadavpur, Kolkata, West Bengal 700032, India

2 Department of Applied Informatics, University of Macedonia, 156 Egnatia str., 54006 Thessaloniki, Greece analysis through setting the realistic limits for decision making. The proposed method has been applied to maintenance technique selection problems of three productive systems of a gear manufacturing organization in India to demonstrate its effectiveness.

Keywords Maintenance techniques · Analytic hierarchy process · Quality function deployment - Benefit of doubt . Stakeholder's needs $\cdot$ Sustainability

\section{Introduction}

Appropriate maintenance of plant equipment and machineries significantly reduces overall operating cost of manufacturing. Additionally, it contributes to customer satisfaction through desired quality and on time delivery. The development of new technologies and managerial practices warrants maintenance crew to ensure having desired technical and managerial skills [1]. Deterioration and failure of systems result to high costs, due to production losses and delays, unplanned intervention on the system and safety hazards. Therefore, appropriate maintenance strategy is necessary in order to prevent failure [2]. Moreover, maintenance crew must select the most appropriate maintenance technique for each machine and manufacturing system out of a set of possible alternatives. In particular, the development of maintenance strategies (i.e. a suitable combination of corrective, preventive and predictive maintenance) must take into account that resource limitation affects maintenance quality [1]. The current practices of the maintenance technique selection are mainly based on the operational criteria in line with machine specification giving utmost importance to the economic factors rather than framing the maintenance strategy based on the strategic importance in combination of technical requirements and efficiency. 
There are number of studies on maintenance technique selection framework development and decision making using operational research techniques [2]. The implementation of advanced manufacturing technologies demands reduction of buffers inventory that increases pressure on selection of most appropriate maintenance technique [3]. Therefore, maintenance technique selection has become strategic that needs attention of both voice of customers' (higher management and production people) and voice of technical persons (maintenance crews). Maintenance performance measurement (MPM) is perceived as an important function to achieve sustainable performance of any manufacturing organization [4]. While maintenance performance indicators have been studied extensively, little has been done to develop a systematic approach that embraces every level of business activities (i.e. strategic, tactical and operational) for maintenance technique selection [5]. A maintenance plan, which is based on a rational assessment of priorities and up to date knowledge of the condition of the facilities and inventory, will help to ensure the best use of available resources. Based on this, a model is presented, using the analytical hierarchy process in deciding the importance of the criteria [6]. With asset availability and reliability becoming critical issues in capital-intensive operation, the strategic importance of maintenance in business is needed to be recognized and maintenance management should be based on certain strategic dimension [7]. Maintenance must be viewed in long-term strategic perspective and must integrate technical and commercial issues. A strategic maintenance approach emphasizes on the quantitative business model that integrate maintenance needs with other operational decisions such as production, procurement, marketing and sales [8]. In their work, Luce [9] selects the best maintenance method using Weibull Law by comparing corrective maintenance, systematic preventive maintenance and conditional preventive maintenance. Parida and Chattopadhyay [10] present a multi-criteria hierarchical maintenance performance measurement framework to resolve this issue although their framework does not provide any guidance on the selection of business specific maintenance engineering methods. Arunraj and Maiti [11] propose an approach of maintenance policy selection based on risk of equipment failure and cost of maintenance using the analytic hierarchy process (AHP) and goal programming (GP). Tan et al. [12] propose a risk-based inspection (RBI) methodology to evaluate the maintenance strategy through probability and consequence of accident or failure. They use the AHP to select the most practicable maintenance strategy for specific equipment. Bertolini and Bevilacqua [13] present a combined AHP-GP model. The AHP prioritizes different maintenance policies with respect to the classical failure mode effect analysis criteria (i.e. occurrence, severity and delectability), and the GP formulates a model that led to identification of the best set of maintenance type for the equipment failure modes considered.

Garcia et al. [14] present application of Intelligent System for Predictive Maintenance (SIMAP) to the health condition monitoring of a wind turbine gearbox. Katchasuwanmanee et al. [15] propose a thermal and energy-management prototype system e-ProMan for application in SME manufacturing environments. Dey [16] contributes a risk-based inspection and maintenance approach for cross-country oil pipeline systems that helps selecting varied maintenance methods for different sections of oil pipelines. The quality function deployment (QFD) has been used by Kutucuoglu et al. [5] to develop performance measurement system in maintenance. Carnero [17] proposes a model that carries out the decision making in relation to the selection of the diagnostic techniques and instrumentation in the predictive maintenance programs. The model uses a combination of the AHP and factor analysis (FA). It considers a number of criteria that help to select the best alternative maintenance technique. Although this method considers both strategic, technical and managerial criteria, it does not build any relationship between management and technical requirements. Bashiri et al. [14] present an approach for selecting optimum maintenance strategy using both qualitative and quantitative data through interactions with the maintenance experts based on linear assignment method (LAM) with interactive fuzzy linear assignment method (IFLAM). Chemweno et al. [19] propose a risk assessment technique in maintenance decision-making domain using the analytic network process. Baidya and Ghosh [18] propose a framework for predictive maintenance indicator effectiveness (PMIE) based on the AHP and analyse the model based on multiple case studies. Wang et al. [20] applied fuzzy AHP methodology to evaluate the best maintenance strategy for different equipment.

In summary, three categories of studies have been undertaken in maintenance technique selection-application of multiple criteria decision-making techniques to accommodate strategic, planning and operational criteria; risk-based approaches that consider both multiple criteria and probabilistic analysis; and failure mode effect analysis (FMEA) approach that allows organization to derive condition of specific equipment or machine objectively through a few rule-based approach and facilitate deriving maintenance method accordingly. The previous studies have also recognized the need of considering strategic intents in maintenance technique selection and incorporated strategic criteria in selection model. However, the methods of identifying those criteria and integrating them with selection model objectively are not clearly explained in these researches. Therefore, there is clear knowledge gap on the processes of capturing strategic information and connecting them to maintenance method selection. This study bridges that gap. Although maintenance method selection for any equipment, machinery and productive system depends on technical specification, cost of maintenance and operational policy, linking them with organizational strategy in one hand enhances productivity of the system and on the other hand ensures overall organizational sustainability.

QFD has been deployed extensively to capture voice of customers for decision making across the functions of 
manufacturing and services operations [21]. QFD has been integrated with multiple criteria decision-making techniques for various decision making. Bhattacharya et al. [22] combine QFD with the AHP for robot selection in manufacturing, Chuang [23] uses for location decision, Hanumaiah et al. [24] apply for rapid hard tooling process selection, Ho et al. [25] adopt for strategic sourcing, and Dey et al. [26] analyse supplier performance. Although the above studies adequately address the consideration of aligning voice of customers with technical requirements in order to make decisions quantitatively across organizational functions and processes, none of the studies precisely address the realistic upper and lower limit of criteria importance for sensitivity analysis of the outcomes (i.e. decision alternatives). This study proposes a holistic maintenance technique selection method that combines both strategic intents of the organization with technical requirements of the maintenance crew in an analytical framework along with the robustness analysis. While QFD integrates strategic, planning and operational requirements of stakeholders across the organizational hierarchy, the AHP prioritizes decision alternatives, and benefit of doubt $(\mathrm{BoD})$ approaches ensure the robustness of the model through introducing confidence interval and sensitivity $\mathrm{BoD}$ analysis. According to the authors' knowledge, the integrated QFD, the AHP and benefit of doubt approach neither has been used in prior studies nor has this been applied in maintenance technique selection.

The paper is organized as follows. Section 2 introduces the proposed integrated QFD, AHP and BoD approach. Section 3 describes the application of the proposed framework within a manufacturing organization in three different types of systems in order to demonstrate its effectiveness. Section 4 elucidates the results and findings from the case studies. Section 5 demonstrates contributions of the study and concludes with information for further scope of research.

\section{Model development}

\subsection{Notation}

\begin{tabular}{|c|c|}
\hline \multicolumn{2}{|l|}{ Indices } \\
\hline$i=1, \ldots, n$ & Customer \\
\hline$j=1, \ldots, m$ & Technical requirement \\
\hline \multicolumn{2}{|l|}{ Parameters } \\
\hline$R_{i j}$ & $\begin{array}{l}\text { Relation between customer } i \text { and technical } \\
\text { characteristic } j\end{array}$ \\
\hline$C_{i}$ & Importance weight for customer requirement $i$ \\
\hline$W_{j}^{\prime, U}$ & $\begin{array}{l}\text { Upper bound on normalized weight corresponding to } \\
\text { technical characteristic } j\end{array}$ \\
\hline$W_{j}^{\prime}{ }^{L}$ & $\begin{array}{l}\text { Lower bound on normalized weight corresponding } \\
\text { to technical characteristic } j\end{array}$ \\
\hline \multicolumn{2}{|l|}{ Variables } \\
\hline$W_{j}$ & Degree of importance for the technical requirement $j$ \\
\hline
\end{tabular}

Normalized importance for the technical requirement $j$

Eigenvector (importance) score of customer $i$ corresponding to technical characteristic $j$

Overall score of technical requirement $j$

\subsection{House of quality}

The concept of house of quality (HoQ) has been first introduced by Houser and Clausing [27]. This house-like diagram provides information regarding the relationship between the customer's needs and how the business/firm will facilitate these needs. HoQ diagram consists of two parts: the relationship between strategic requirements of the higher management and operational needs of maintenance group, and the relationship between maintenance group's requirements and alternative maintenance techniques/technologies. These two HoQs facilitate derive relative ranking of maintenance methods using QFD [28] framework.

\subsection{The proposed QFD-AHP-BoD approach}

In order to utilize the information provided by QFD and derive the degree of importance of customer's requirements towards tangible and intangible technical characteristics, a QFD-AHP approach is adopted in this paper. The AHP is a multiple criteria decision-making (MCDM) technique, developed by Saaty [29], where aiming at capturing the intra-relationships between criteria, both tangible and intangible through pairwise comparison. A graphical outline of the paper is presented in (Fig. 1); two HoQs are presented (HoQ-I and HoQII). In HoQ-I, the rows represent strategic requirements while columns the technical requirements. In HoQ-II, the rows represent technical requirements and columns represent alternate maintenance techniques. BoD [30] approach has been adopted to check the robustness of the proposed method through setting upper and lower limits of criteria weight.

The comparisons are made using a scale of absolute judgements that represents how much more one element dominates another with respect to a given attribute [29]. Inconsistency is a major problem of the AHP methodology [29]. The index that measures consistency in the AHP is consistency ratio (CR). For the calculation of CR, consistency index (CI) which is calculated in (1) and random index (RI) must be provided; $\mathrm{RI}$ is a fixed number based on the dimensions of a pairwise comparison matrix $A_{i j}$.

$\mathrm{CI}=\frac{\lambda^{\mathrm{max}}-n}{n-1}$

In (1), $\lambda^{\max }$ stands for the largest eigenvalue of a pairwise comparison matrix $A_{i j}$ of dimensions $n \times n$, while fixed values regarding RI are given in Table 1. Finally, CR, which is the 
Fig. 1 Graphical representation of QFD-AHP methodology

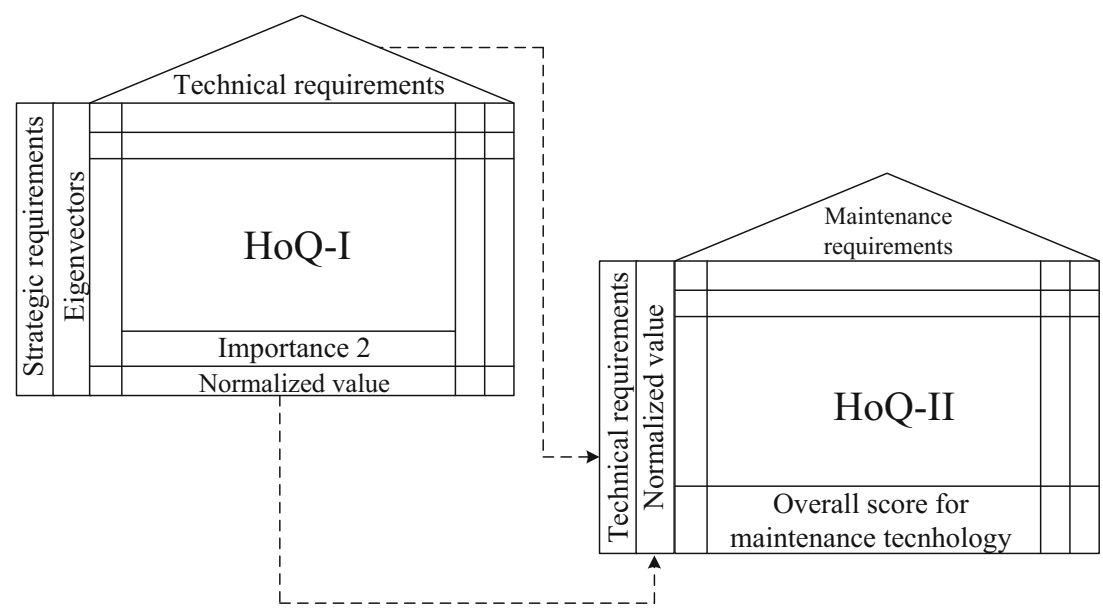

measure based on whether pairwise comparisons are consistent or not, is defined as the quotient of CI to RI.

$\frac{\mathrm{CI}}{\mathrm{RI}}=\mathrm{CR}\left\{\begin{array}{l}\leq 10 \% \text { consistent } \\ >10 \% \text { inconsistent }\end{array}\right.$

Other constraints of the AHP has been demonstrated elsewhere [16].

QFD was first applied by Japanese manufacturing organizations to meet customers' requirements throughout the design process and also in the design of production systems. A matrix is used to present data and information [31]. A full QFD application may make use of several HoQ diagrams, forming a sequence that gradually translate customer requirements into specific manufacturing steps and detailed manufacturing step requirements. Furthermore, QFD methodology is an overall concept that provides a means of translating customer requirements into the appropriate technical requirements for each stage of product development and production (i.e. marketing strategies; planning, product design and engineering; prototype evaluation; production process development; production; sales) [32].

In this study, two HoQs have been used for the model development, linking the multiple criteria to form an effective decision making model. The generic model development has been explained below in steps.

1. The strategic managerial requirement was identified from the concerned expert group and also verified from the literature. This constructs/criteria are the "WHATs" of the HoQ-I. The importance of this constructs/criteria was derived through pairwise comparison based on the AHP.
2. The technical criteria were identified based on the requirements of the maintenance group and the critical parts considered for the study. These constructs/ criteria are the "HOWs" of the HoQ-I. The relationship rating based on predefined scales 9, 3, 1 and 0 indicating strong relationship, medium relationship, weak relationship and no relationship respectively, is obtained. These ratings were obtained from the same expert groups. This analysis yielded the degree of importance (importance-2) of each of the technical criteria by correlating with the managerial requirements. Assuming that there are $j=1, \ldots, n$ technical requirements and customer requirements, the computation of degree of importance is performed as

$$
W_{j}=\sum_{i=1}^{m} R_{i j} \cdot C_{i}, j=1, \ldots n
$$

In (2), $W_{j}$ is an $n \times 1$ vector representing the degree of importance between technical requirement $j$ and is defined as the product or quantified relationships between customer requirement $i$ and technical requirement $j\left(R_{i j}\right)$, as well as importance weighting of customer requirement $i\left(C_{i}\right)$.

3. Degree of importance is further normalized by dividing each element $w_{j}$ of vector $W_{j}$ by the sum of all the

Table 1 Values for random index (RI) based on the dimensions of pairwise matrix $A$

\begin{tabular}{lllllllllll}
\hline Number & 1 & 2 & 3 & 4 & 5 & 6 & 7 & 8 & 9 & 10 \\
\hline RI & 0 & 0 & 0.58 & 0.9 & 1.12 & 1.24 & 1.32 & 1.41 & 1.45 & 1.49 \\
\hline
\end{tabular}


elements. The resulting normalized score for each technical requirement $j$ is denoted as $W_{j}^{\prime}$ and yields a value in the range of $[0,100] \%$.

$$
W_{j}^{\prime}=\frac{w_{j}}{\sum_{j=1}^{n} W_{j}}, j=1, \ldots n
$$

4. The technologies available for the considered critical parts were identified from the literature, and a HoQ-II was developed. The WHATs part in HOQ-II relationship matrix are the technical criteria of the HOQ-I, and the HOWs are the technologies considered for the critical parts.

5. Finally, the AHP analysis is applied for the examined technologies based on each and every maintenance group; constructs/criteria are used to obtain the importance/Eigen vector $\left(E_{i j}\right)$ for each alternative technology. The overall score for each requirement $j$ denoted as $S_{j}$ is calculated by summing over index $j$, the product of the normalized score for each technical requirementjwith eigenvector score derived for each customer requirement $i$ and technical requirement $j$.

6. Taking all the information regarding the normalized weights $W_{j}^{\prime}$, a linear programming (LP) model is formed in order to investigate the sensitivity of each weight with bound and preference constraints.

$S_{j}=\sum_{i=1}^{m} W_{j}^{\prime} \cdot E_{i j}, j=1, \ldots n$

The ranking of the maintenance technology is based on the overall score as derived from step 5 [22]. The proposed methodology is graphically summarized in Fig. 2.

The analysis employed is based on data envelopment analysis (DEA) technique and especially on $\mathrm{BoD}$ with bound and preference constraints. The optimal weights are calculated based on a LP model. The hierarchy formed in HoQ-II is shown in Fig. 3.

Based on that hierarchical structure, the optimal weights are to be calculated in order to provide a ranking for technical requirements. Weights assigned to each "branch" come from HoQ-I, and the target in that analysis is to recalculate the weights $W_{j}^{\prime}$ based on the proposed BoD model. The aim of the LP model is to maximize $S_{j}$, which in this case is serving used as a CI. Based on (5), the objective function (6) is to maximize the overall score $\sum_{j} S_{j}$, while this score should yield a maximum value of 1 so constraint (8) is introduced in order to bound each score to 1. Weights that are calculated in HoQ-I are used as initial points and bounds are constructed. Thus, each initial weight value is eventually corrected based on an initial estimation of the weights calculated from HoQ-I. Therefore, constraints (9) and (10) are formulating the bounds placed on each weight. Finally, preference constraints are introduced in order to retain the order of weights provided from HoQ-I. Non-negativity constraint (12) is introduced to prevent each weight of taking a negative value.

$\max \sum_{j} S_{j}$

s.t.

$S_{j}=\sum_{i=1}^{m} W_{j}^{\prime} \cdot E_{i j}, j=1, \ldots n$

$\sum_{i=1}^{m} W_{j}^{\prime} \cdot E_{i j} \leq 1, \quad j=1, \ldots n$

$W_{j}^{\prime} \leq W_{j}^{\prime}, U, j=1, \ldots n$

$W_{j}^{\prime} \geq W_{j}^{\prime, L}, \quad j=1, \ldots n$
Fig. 2 Graphical representation of the proposed QFD-AHP methodology

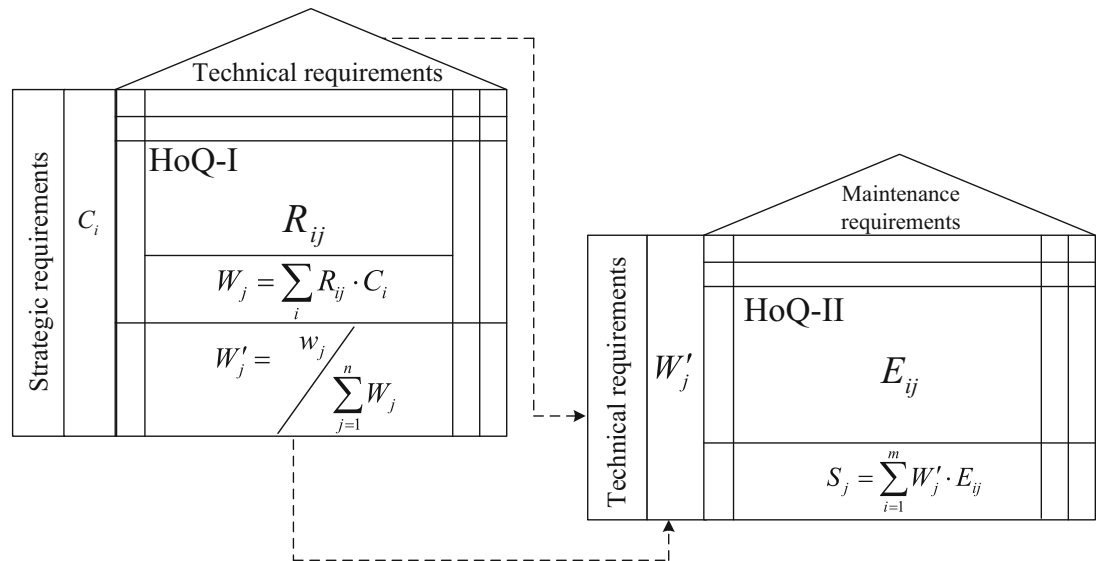


$\operatorname{pref}\left(W_{j=A}^{\prime}, W_{j=B}^{\prime}\right)$

$W_{j}^{\prime} \geq 0, j=1, \ldots n$

Upper and lower bounds of constraints (9) and (10) that correspond, placed on weights $W_{j}^{\prime}$, are constructed based on the weights derived from HoQ-I. Following that, scenarios on upper and lower bounds are considered with the following procedure presented in pseudo-code in (13). As it can be seen in (13), upper and lower bounds as presented in constraints (9) and (10) are calculated based on the initial value of $W_{j}^{\prime}$. The increment based on which ranges are constructed is based on $O R D$ function which corresponds the order of set $s c$ with a number. If upper bound value exceeds 1 or lower bound becomes a negative number, then a readjustment is made. This procedure implies that the presented LP model is solved $s c$ times. In this case, 50 scenarios were assumed for bounds starting from \pm 1 to $\pm 20 \%$.

$$
\begin{aligned}
& \text { for } s c=1, \ldots, s c \\
& W_{j}^{\prime}{ }_{j}^{U, s c}=\left(1+\frac{O R D(s c)}{100}\right) \cdot W_{j}^{\prime} \\
& W_{j}^{\prime L, s c}=\left(1-\frac{O R D(s c)}{100}\right) \cdot W_{j}^{\prime} \\
& \operatorname{if}\left({W^{\prime}}_{j}^{U, s c}>1 \text { OR } W_{j}^{\prime L, s c}<0\right) \\
& W_{j}^{\prime U, s c}=1 \\
& W_{j}^{L, s c}=0 \\
& \text { end if }
\end{aligned}
$$

end for

Preference set of constraint (11) is introduced to retain the ranking of the criteria (technical requirements) based on the weights derived from HoQ-I.

\section{Model application on case study}

\subsection{Step by step approach}

The proposed model has been applied to a gear manufacturing organization in India to demonstrate its effectiveness. Gears

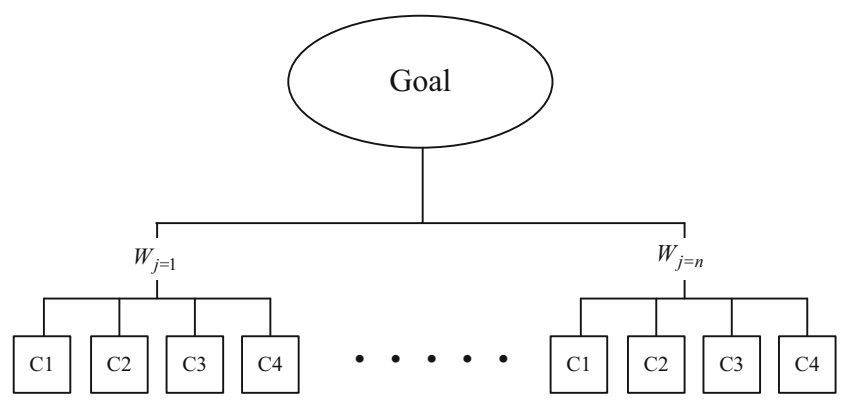

Fig. 3 Hierarchy structure in HoQ-II are the integrated parts of machines for power transmission. With the advancement of technology, gear manufacturing comes under one of the hi-tech manufacturing industries. It deploys complex machineries and needs sophisticated technologies/techniques for maintenance. Gear manufacturing is in growing trend in India with the recent advancement of automotive industry. However, most appropriate maintenance technique selection for various systems within a complex machine is still challenging. The company under study manufactures a wide variety of gears with turnover of 6 million pound. The organization deploys modern machines, and equipment in their production line and maintenance services are provided by a dedicated maintenance department. The modern state of the art machines are maintained by the original equipment manufacturers (OEMs). The manufacturing/production and maintenance groups work closely in order to keep the production up to the target. The following paragraphs demonstrate the application using step by step approach.

Step 1: The board of directors including the production director of the concerned organization was engaged for the case study in order to identify their requirements through the voice of customer (VOC). The requirements of the board members and the concerned stakeholders were obtained in a focussed group of five persons - the finance director, marketing director, production directors, general manager and production manager. The following constructs/ criteria $[33,34]$ were derived from their requirements return on investment, running cost, reliability, operability, flexibility, machine availability, safety, resource utilization and energy consumption

The importance of each criterion is determined using pairwise comparison following the AHP approach with the involvement of the concerned stakeholders. These criteria are the WHATs for the HoQ-I (that is the first QFD relationship matrix), and their ratings were obtained from the same focussed group using questionnaires survey. The questioner was prepared for the collection of the qualitative data so as to analyse the decision model. The questionnaire was developed based on the obtained constructs and their relationships. The answers were obtained on a predefined scale of AHP and QFD. The answers were obtained from executives of the participating organization. The participating executives are all functional experts in manufacturing and maintenance and having more than 15 years of industry experience. Table 2 shows the results of pairwise comparison and relative importance of criteria as well as consistency ratio.

Step 2: The strategic maintenance requirement of the concerned organization was identified through brainstorming session with the selected focussed 
Table 2 Pairwise comparison matrix for degree of importance considering the managerial aspects

\begin{tabular}{|c|c|c|c|c|c|c|c|c|c|c|c|}
\hline $\begin{array}{l}\text { Major customer } \\
\text { (managerial) } \\
\text { aspects }\end{array}$ & $\begin{array}{l}\text { Return on } \\
\text { investment }\end{array}$ & $\begin{array}{l}\text { Running } \\
\text { cost }\end{array}$ & Reliability & Operability & Flexibility & $\begin{array}{l}\text { Machine } \\
\text { availability }\end{array}$ & Safety & $\begin{array}{l}\text { Resource } \\
\text { utilization }\end{array}$ & $\begin{array}{l}\text { Energy } \\
\text { consumption }\end{array}$ & $\begin{array}{l}\text { Eigen } \\
\text { vector }\end{array}$ & $\mathrm{CR}$ \\
\hline $\begin{array}{l}\text { Return on } \\
\text { Investment }\end{array}$ & 1 & 3 & 0.333 & 3 & 3 & 1 & 0.333 & 5 & 1 & 0.12028 & 0.09848 \\
\hline Running cost & 0.333 & 1 & 1 & 1 & 3 & 3 & 0.333 & 3 & 1 & 0.1051 & \\
\hline Reliability & 3 & 1 & 1 & 3 & 5 & 3 & 0.333 & 5 & 3 & 0.17522 & \\
\hline Operability & 0.333 & 1 & 0.333 & 1 & 3 & 0.333 & 0.142 & 3 & 2 & 0.06666 & \\
\hline Flexibility & 0.333 & 0.333 & 0.2 & 0.333 & 1 & 0.2 & 0.142 & 2 & 3 & 0.04578 & \\
\hline Machine Availability & 1 & 0.333 & 0.333 & 3 & 5 & 1 & 0.333 & 3 & 2 & 0.10222 & \\
\hline Safety & 3 & 3 & 3 & 7 & 7 & 3 & 1 & 7 & 5 & 0.30198 & \\
\hline Resource Utilization & 0.2 & 0.333 & 0.2 & 0.333 & 0.5 & 0.333 & 0.142 & 1 & 0.333 & 0.02575 & \\
\hline $\begin{array}{l}\text { Energy } \\
\quad \text { Consumption }\end{array}$ & 1 & 1 & 0.333 & 0.5 & 0.333 & 0.5 & 0.2 & 3 & 1 & 0.05700 & \\
\hline
\end{tabular}

maintenance group consisting of five of the top maintenance group board members and other stakeholder members, including R\&D department engineers, chief maintenance engineer, chief plant engineer and production engineer. These requirements are the HOWs for the HOQ-I. The focussed group identified the three critical parts of the machines for the study. They were bearing system, gear system and lubrication system. Vibration analysis, acoustic emission, shock pulse method and oil analysis are considered as alternative maintenance techniques for bearing and gear systems. For lubrication system, the alternative maintenance techniques are process parameter, performance monitoring and oil analysis. The requirements of maintenance department were derived through brainstorming with the involvement of experienced maintenance crew. The technical requirements are as follows: (a) indicating cost of setup, (b) number of probes required, (c) maintenance time required, (d) time for setup, (e) meets maintenance standards, (f) breakdown/ corrective maintenance reduction, (g) life cycle of the setup, (h) frequency of equipment inspection, (i) support equipment required, (j) technical expertise required for maintenance, $(\mathrm{k})$ effectiveness of the setup and (l) reparability of the setup. The following paragraph briefly describes the proposed alternative maintenance methods.

Vibration analysis still remains the most popular maintenance technology for rotating equipment [35]. Its applications have been presented for monitoring the gearbox [36] and the bearings $[37,38]$. The measurement and interpretation of acoustic emissions (AE) parameters for fault detection in radially loaded ball bearings have been demonstrated at different speed ranges [39]. In addition, the application of $\mathrm{AE}$ for the detection of bearing failures has been presented by Tan [40]. Little or no vibration may be evident while faults are developing, but analysis of the oil can provide early warnings; a case study of a wind turbine gearbox is presented by Leske and Kitaljevich [41]. Shock pulse method (SPM) has been used as a quantitative method for condition monitoring of bearings and works by detecting the mechanical shocks that are generated when a ball or roller in a bearing comes in contact with a damaged area of raceway or with debris [42]. Signals are picked up by transducers, and analysis gives an indication of system condition [43]. Process parameters are the maintenance based on the detection of signals exceeding predefined control limits, control systems becoming increasingly sophisticated and diagnostic capabilities even better. Transient and oscillatory stabilities were analysed with different wind scenarios for electricity generation process [44]. Zaher and McArthur [45] give an explanation of the use of signals and trending for fault detection based on parameter estimation. Performance monitoring analysis the relationship between parameters such as power, wind speed, blade angle and rotor speed for an assessment of wind turbine condition and for the early detection of faults [46].

Step 3: The strategic/managerial criteria and the maintenance group requirements relationship were correlated according to QFD scale (strongly, moderately and weekly related and no relationship). The participants developed consensus on every relationship through brainstorming. Their responses were considered along with the importance of the strategic requirements in order to determine overall importance of the criteria/requirements of the maintenance group using Eqs. (3) and (4) (Fig. 2). The HoQ-I (Table 3) depicts the numerical figures for the case 
study organization. The outcome of this step is the importance of the requirements of maintenance group.

Step 4: In this step, the relative priority of alternative maintenance techniques against each criteria as derived by the maintenance group was revealed using pairwise comparison in the AHP framework. The participants consensually provide the rating using Saaty's scale [29]. The outcomes of the pairwise comparisons along with relative priorities of each maintenance technique for the bearing system were derived; one of them has been depicted in Table 4.

Step 5: The importance/Eigen vector $\left(E_{i j}\right)$ for each alternative technology/technique obtained from the above step was used as the relationship rating for the HOQII. The importance of each criterion of maintenance group's requirements came from step 3. The overall relative weights and ranking of the maintenance techniques were derived using Eq. (5), as it can be seen in Fig. 2. The HoQ-II for bearing system, gear system and lubricating system are shown in Tables 5, 6 and 7 respectively.

Step 6: In this section, a robustness analysis is performed for the evaluation of weights assigned to each technical requirementj. The notion behind this meta-analysis is to identify weight's variability and therefore to examine how robust is the decision made, from the insight of the decision maker. In other words, the analysis provides a level of how certain the decision maker could be when ranking the technical requirements in term of weights. Generally, this technique is applied for composite indicators but is flexible and presents information regarding the weights and value of each criterion based on preselected alternatives [47].

For illustrative purposes, an application is demonstrated in "Bearing system framework for company" presented in Table 5, but the proposed sensitivity analysis can be applied to the other systems (gear system, lubrication system). The technical requirements are denoted with numbers: (1) cost of setup, (2) number of probes required,..., (12) reparability of the setup. Based on Table 5 (weight column), it is assumed that $4 \prec 3 \prec 7 \prec 9 \prec 12 \prec 1 \prec 11 \prec 10 \prec 8 \prec 2 \prec 5 \prec 6$, whereas $\prec$ indicates the preference of a technical requirement over another; for instance, $5 \prec 6$ is translated as 6 is preferred from 5 . To that end, a technical requirement $A$ which is preferable from a technical requirement $B$ is modelled with constraint (13).

$W_{j=A}^{\prime} \succ W_{j=B}^{\prime} \rightarrow W_{j=A}^{\prime} \geq W_{j=B}^{\prime}+\varepsilon$

In (14), $\varepsilon$ stands for a very small positive number and is introduced in order to exclude the fact that two weights will have the same value; a modified BoD model ((6)-(12)) provides the optimal readjusted weights of the hierarchy form presented in Fig. 3. Preference set of constraints introduced in (13) is analysed with the constraints regarding preferences (15)-(25).

$$
\begin{aligned}
& W_{j=6}^{\prime} \geq W_{j=5}^{\prime}+\varepsilon \\
& W_{j=5}^{\prime} \geq W_{j=2}^{\prime}+\varepsilon \\
& W_{j=2}^{\prime} \geq W_{j=8}^{\prime}+\varepsilon \\
& W_{j=8}^{\prime} \geq W_{j=10}^{\prime}+\varepsilon \\
& W_{j=10}^{\prime} \geq W_{j=11}^{\prime}+\varepsilon \\
& W_{j=11}^{\prime} \geq W_{j=1}^{\prime}+\varepsilon \\
& W_{j=1}^{\prime} \geq W_{j=12}^{\prime}+\varepsilon \\
& W_{j=12}^{\prime} \geq W_{j=9}^{\prime}+\varepsilon \\
& W_{j=9}^{\prime} \geq W_{j=7}^{\prime}+\varepsilon \\
& W_{j=7}^{\prime} \geq W_{j=3}^{\prime}+\varepsilon \\
& W_{j=3}^{\prime} \geq W_{j=4}^{\prime}+\varepsilon
\end{aligned}
$$

After solving BoD model, the following results regarding weight ranges are presented in Table 8 .

Based on the approach presented above, let us see an example of the applicability of the sensitivity analysis. The normalized weight assigned to cost of setup (technical requirement 1) is 0.482 . In order to measure the sensitivity of each weight that corresponds to technical requirements with respect to the values, the following bounds are considered for each scenario. The bounds, as shown in (26) and (27), correspond to a $\pm 1 \%$ deviation in the base value of the weight for scenario 1 .

$W_{j=1}^{\prime} \leq 1.1 \cdot 0.482=0.4871$

$W_{j=1}^{\prime} \geq 0.99 \cdot 0.482=0.4775$

Solving BoD model with objective function (6) and constraints (7)-(12), the weight $W_{j=1}^{\prime}$ yields an optimal value of 0.4851 . The corresponding bounds for scenario 50 are given by $[0.3858,0.5788]$, while the optimal value for scenario 50 of $W_{j=1}^{\prime}$ is 0.5768 . As ranges do not provide a representative image of each weight's variability, standard deviation measure is employed for each range (Fig. 4).

In Table 8, the range of each technical requirement is calculated with respect to minimum and maximum values for each scenario.

According to Fig. 4, the technical requirements with the smallest variability are 5, 6 and 2, while the one with the 


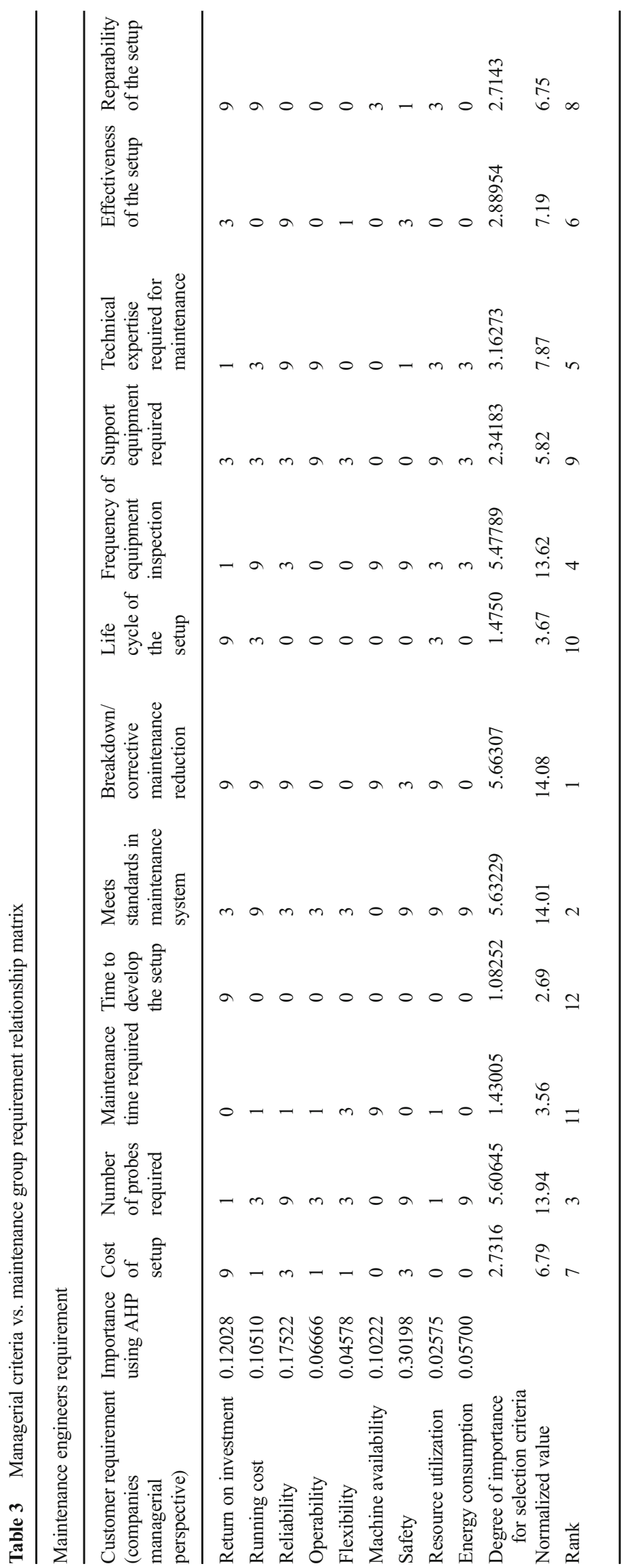


Table 4 Pairwise comparison matrix at alternatives level based on cost of setup for bearing system

\begin{tabular}{llllll}
\hline $\begin{array}{l}\text { Alternative for cost } \\
\text { of setup }\end{array}$ & Vibration analysis & Acoustic emission & Shock pulse method & Oil analysis & Eigen vector \\
\hline Vibration analysis & 1 & 3 & 3 & 0.333 & 0.26534 \\
Acoustic emission & 0.333 & 1 & 3 & 0.333 & 0.15118 \\
Shock pulse method & 0.333 & 0.333 & 1 & 0.2 & 0.0752 \\
Oil analysis & 3 & 3 & 5 & 1 & 0.50829 \\
\hline
\end{tabular}

largest is technical requirement 10 . From this analysis, it can be concluded that the decisions regarding technical requirements with smallest variability in the weight ranges are more stable than those with largest variability in the weight ranges.

\section{Results and findings}

This section demonstrates the specific findings from the application of the proposed framework in the case study organization. Three most strategic requirements of the management of the case study organization were safety, reliability and return on investment in sequence. In line with strategic intents of maintenance, the maintenance group's prioritized requirements were "corrective maintenance reduction", "meets standard of a maintenance system", "number of probes required" and "frequency of equipment inspection". Overall, the combined QFD and the AHP analysis reveal that "shock plus method", "vibration analysis" and "process parameter" were selected for bearing, gear and lubricating system respectively. The analysis for bearing revealed that the shock pulse method with overall score 28.07 was the best followed by acoustic emission with overall score of 24.19 and the worst was oil analysis with value of 23.57. In a similar way, the analysis of the gear system was done and it revealed that vibration analysis was the most effective technology followed by acoustic emission, and on analysing the lubrication system, the most effective technology/technique was process parameters followed by the oil analysis. Surprisingly, technologies with the least importance for all the system except for the lubrication analysis was found to be oil analysis, which the case study organization used to deploy prior to this study for every maintenance need.

Currently, the oil analysis is deployed for maintenance as this option is less expensive compared to other techniques. However, the strategic intents/managerial requirements are not aligned with current approach to selected maintenance technique. The combined QFD and the AHP method provide a robust and holistic approach to select the right maintenance technique for specific system. For the gear system, the vibration analysis was the best followed by the acoustic emission. For the bearing systems, shock pulse method was the best followed by acoustic emission. The analysis of the lubrication system also indicated that the process parameter is the best which is an inbuilt system in any machinery. The company should exclude the oil analysis from the maintenance system

Table 5 Bearing system framework for company

Overall importance of the maintenance technologies

\begin{tabular}{|c|c|c|c|c|c|c|}
\hline Technical requirements & Weight & Vibration analysis & Acoustic emission & Shock pulse method & Oil analysis & $\mathrm{CR}$ \\
\hline Cost of setup & 6.79392 & 0.26534 & 0.15118 & 0.0752 & 0.50829 & 0.07418 \\
\hline Number of probes required & 13.94383 & 0.27624 & 0.11815 & 0.11815 & 0.48745 & 0.05787 \\
\hline Maintenance time required & 3.55668 & 0.24725 & 0.48268 & 0.17614 & 0.09393 & 0.08062 \\
\hline Time to develop the setup & 2.69234 & 0.15006 & 0.37218 & 0.37218 & 0.10558 & 0.02271 \\
\hline Meets standards in maintenance system & 14.00809 & 0.1713 & 0.35867 & 0.40113 & 0.0689 & 0.01279 \\
\hline Breakdown/corrective maintenance reduction & 14.08465 & 0.14858 & 0.32485 & 0.46005 & 0.06653 & 0.03901 \\
\hline Life cycle of the setup & 3.66865 & 0.26094 & 0.16893 & 0.11896 & 0.45117 & 0.0266 \\
\hline Frequency of equipment inspection & 13.62408 & 0.45086 & 0.19779 & 0.25742 & 0.09393 & 0.08062 \\
\hline Support equipments required & 5.82438 & 0.16362 & 0.2829 & 0.44755 & 0.10592 & 0.0266 \\
\hline Technical expertise required for maintenance & 7.86604 & 0.26283 & 0.14088 & 0.14088 & 0.45541 & 0.00388 \\
\hline Effectiveness of the setup & 7.18659 & 0.12218 & 0.29762 & 0.52317 & 0.05703 & 0.02567 \\
\hline Reparability of the setup & 6.75077 & 0.25742 & 0.14697 & 0.11293 & 0.48268 & 0.08062 \\
\hline Overall score & & 24.16633448 & 24.19439216 & 28.0661584 & 23.573146 & \\
\hline Rank & & 3 & 2 & 1 & 4 & \\
\hline
\end{tabular}


Table 6 Gear system framework for company

Overall importance of the maintenance technologies

\begin{tabular}{|c|c|c|c|c|c|c|}
\hline Technical requirements & Weight & Vibration analysis & Acoustic emission & Shock pulse method & Oil analysis & $\mathrm{CR}$ \\
\hline Cost of setup & 6.79392 & 0.24761 & 0.12926 & 0.07364 & 0.54949 & 0.07418 \\
\hline Number of probes required & 13.94383 & 0.48268 & 0.24725 & 0.17614 & 0.09393 & 0.08062 \\
\hline Maintenance time required & 3.55668 & 0.15235 & 0.38986 & 0.38986 & 0.06792 & 0.01629 \\
\hline Time to develop the setup & 2.69234 & 0.16864 & 0.3679 & 0.3679 & 0.09557 & 0.05787 \\
\hline Meets standards in maintenance system & 14.00809 & 0.4258 & 0.30109 & 0.2129 & 0.06022 & 0.04544 \\
\hline Breakdown/corrective maintenance reduction & 14.08465 & 0.51095 & 0.26264 & 0.15997 & 0.06644 & 0.04923 \\
\hline Life cycle of the setup & 3.66865 & 0.39513 & 0.22146 & 0.31011 & 0.0733 & 0.09258 \\
\hline Frequency of equipment inspection & 13.62408 & 0.52224 & 0.19983 & 0.19983 & 0.07809 & 0.01629 \\
\hline Support equipments required & 5.82438 & 0.32057 & 0.27801 & 0.31568 & 0.08574 & 0.0952 \\
\hline Technical expertise required for maintenance & 7.86604 & 0.52812 & 0.21 & 0.21 & 0.05188 & 0.02752 \\
\hline Effectiveness of the setup & 7.18659 & 0.52234 & 0.2498 & 0.17682 & 0.05103 & 0.05024 \\
\hline Reparability of the setup & 6.75077 & 0.25073 & 0.15749 & 0.10343 & 0.48835 & 0.05361 \\
\hline Overall score & & 42.60217519 & 24.28425388 & 19.88859208 & 13.224922 & \\
\hline Rank & & 1 & 2 & 3 & 4 & \\
\hline
\end{tabular}

unless the strategic maintenance requirement is changed as it showed the least importance in most of the analysis. The oil analysis for lubrication system can be used as secondary maintenance technology/technique as it is the most effective technologies for lubrication system analysis. Hence, this study provided effective way of obtaining the most effective technology based on the strategic needs of the organization. It has also been revealed from the case study that the organization was selecting maintenance technique on economic criteria alone without considering sustainability issues. The research presents an approach for an effective and sustainable maintenance system selection model. The model also provides an effective designing methodology for any company's maintenance needs; the change of managerial criteria and there degree of importance or the maintenance group requirements can alter the result. Thus, this model is versatile for designing an effective maintenance management system according to the need of the industries. The consolidated results (selection of specific maintenance technique) of the case study is given in Table 9. The proposed analysis is linked with BoD approach and is used as a second stage analysis in order to measure the sensitivity of the weights preferences (decisions).

Table 7 Lubrication system framework for company

Overall importance of the maintenance technologies

\begin{tabular}{lcccc}
\hline Technical requirements & Weight & Process parameters & Performance monitoring & Oil analysis \\
\hline Cost of setup & 6.79392 & 0.52784 & 0.33252 & 0.13965 \\
Number of probes required & 13.94383 & 0.58155 & 0.05156 \\
Maintenance time required & 3.55668 & 0.18517 & 0.109 & 0.00355 \\
Time to develop the setup & 2.69234 & 0.48064 & 0.15618 & 0.65864 \\
Meets standards in maintenance system & 14.00809 & 0.15706 & 0.40539 & 0.11397 \\
Breakdown/corrective maintenance reduction & 14.08465 & 0.24931 & 0.24931 & 0.02795 \\
Life cycle of the setup & 3.66865 & 0.48064 & 0.40539 & 0.05156 \\
Frequency of equipment inspection & 13.62408 & 0.52784 & 0.33252 & 0.05156 \\
Support equipments required & 5.82438 & 0.58155 & 0.309 & 0.11397 \\
Technical expertise required for maintenance & 7.86604 & 0.40539 & 0.4806 & 0.13965 \\
Effectiveness of the setup & 7.18659 & 0.17862 & 0.05156 \\
Reparability of the setup & 6.75077 & 0.25828 & 0.11252 & 0.10945 \\
Overall score & & 37.91 & 0.10473 & 0.11397 \\
Rank & & 1 & 27.033 & 0.00355 \\
\hline
\end{tabular}


Table 8 Ranges of weights for each technical requirement

\begin{tabular}{|c|c|c|c|c|c|c|}
\hline & & $\min _{s c}\left\{W_{j}^{\prime U, s c}\right\}$ & $\max _{s c}\left\{W_{j}^{\prime U, s c}\right\}$ & & $\min _{s c}\left\{W_{j}^{\prime}{ }_{j}^{U, s c}\right\}$ & $\max _{s c}\left\{W_{j}^{\prime U, s c}\right\}$ \\
\hline \multirow{6}{*}{$\begin{array}{l}\text { Technical } \\
\text { requirement }\end{array}$} & $\mathrm{T} 1$ & 0.48519 & 0.57684 & $\mathrm{~T} 7$ & 0.26208 & 0.31157 \\
\hline & $\mathrm{T} 2$ & 0.99790 & 0.99799 & $\mathrm{~T} 8$ & 0.97397 & 0.99699 \\
\hline & $\mathrm{T} 3$ & 0.25305 & 0.30103 & T9 & 0.41766 & 0.49623 \\
\hline & $\mathrm{T} 4$ & 0.19007 & 0.22639 & $\mathrm{~T} 10$ & 0.56407 & 0.67018 \\
\hline & $\mathrm{T} 5$ & 0.99899 & 0.99899 & $\mathrm{~T} 11$ & 0.51435 & 0.61129 \\
\hline & T6 & 0.99999 & 0.99999 & $\mathrm{~T} 12$ & 0.48109 & 0.57216 \\
\hline
\end{tabular}

The weights that are derived by QFD-AHP approach are recalculated. The weights are not considered to be fixed, and sensitivity of the weights is calculated as a means of robustness (Fig. 4).

\section{Discussion and conclusion}

Maintenance technique selection has strategic significance as production system's availability is directly connected to any manufacturing organization's economic performance. Currently, maintenance techniques are selected mainly on the basis of specific technical needs of the production system along with economic factors only. In other words, technically feasible least cost option is considered for maintenance technique selection. This causes several issues as quite often least cost option is not the best in long term as well from total cost ownership perspectives. Additionally, consideration of

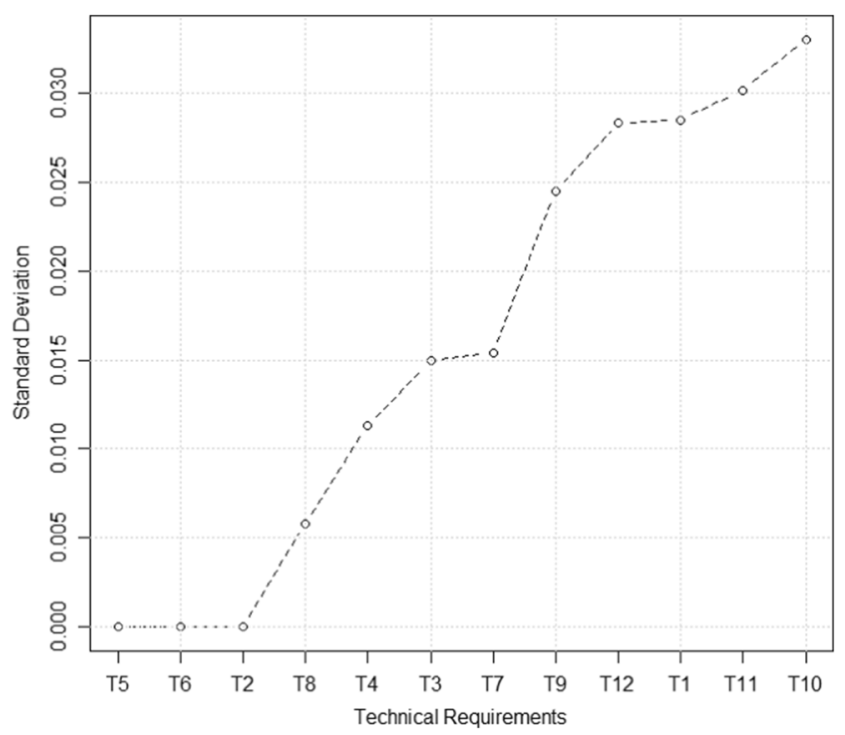

Fig. 4 Standard deviation for technical requirements ranges environmental and social criteria helps achieve image for global reach. Therefore, there is need for analysing the issue from holistic perspectives considering the strategic intents of maintenance of productive unit and identifying criteria for maintenance technique selection more objectively with the involvement of concerned stakeholders. This study considers both strategic/managerial criteria and requirements of the maintenance group for developing a framework for selecting most appropriate maintenance technique. The framework is based on three decision-making techniques - quality function deployment (QFD), the analytic hierarchy process (AHP), and benefit of doubt (BoD). They are combined together to form a decision support system that enables organizations to select the right maintenance technique for specific system/machinery/equipment. The framework needs active participation of the concerned stakeholder to identify the constructs for selection, derive the importance, prioritize of the alternative maintenance techniques and analyse sensitivity of the decisions through robustness calculation. The proposed framework is dynamic and flexible and can accommodate varied criteria as per the needs of the stakeholders.

The case study reveals that prior to the application of the proposed framework, the organization under study emphasized on economic factor while selecting maintenance techniques for their production system. However, the study derives that the strategic emphasize of the organization's maintenance needs are reliability, safety and return on investment. As the organization currently emphasizes on efficiency in their maintenance techniques selection, there exist a clear mismatch between their strategic intents and operational decision. The two-stage analysis (as shown in HoQ-I and HoQ-II) reflects consideration of varied criteria in strategic and operational levels, their importance as derived with the involvement of the concerned stakeholders and overall priorities of the maintenance techniques selection using combined QFD and the AHP approach. Additionally, the robustness analysis of the importance of technical requirements is conducted. Based on bounds placed on the weights derived from HoQ-I, bounds are introduced as constraints, while preference constraints 
Table 9 Rank of the technologies of the critical parts

\begin{tabular}{llll}
\hline Rank/effectiveness & Lubrication system & Bearing system & Gear system \\
\hline 1 & Process parameter & Shock pulse method & Vibration analysis \\
2 & Oil analysis & Acoustic emission & Acoustic emission \\
3 & Performance monitoring & Vibration analysis & Shock pulse method \\
4 & - & Oil analysis & Oil analysis \\
\hline
\end{tabular}

guarantee the order to each technical requirement. Based on this analysis, the most sensitive to changes, weight is derived. The outcomes of the analysis reveal that for all the three cases the selection was on the basis of holistic criteria with less emphasize on maintenance cost. Maintenance quality, environment friendliness and greater sustainability received more importance and techniques that are aligned with these criteria got selected. Therefore, the proposed framework provides a robust approach that can be applied to any situation for maintenance technique selection within a productive system in line with both strategic and operational needs of the stakeholders.

Although maintenance system technique/technology selection using multiple criteria decision making techniques has been researched extensively, very little work has been done to capture stakeholders' perspectives in maintenance decision-making models very systematically. This study bridges this gap by integrating stakeholders' requirements in model building using QFD. Additionally, although the combined QFD and the AHP approach have been used in prior research, there is no study that uses combined QFD and the AHP for selecting maintenance technique. Therefore, this study contributes an integrated decision support system for maintenance technique selection to improve overall productivity of manufacturing organizations.

The proposed framework addresses one of the most important aspects of maintenance procedure; the effectiveness of the technologies used in CBM and simultaneously meets the objective requirements of the strategic needs of the organization and the needs of maintenance engineers. This develops synergy between operational needs and the strategic intents of the organization. The proposed framework also enables to eliminate least effective and obsolete technologies from company's maintenance policy so as to make the organization more productive. The proposed combined QFD, the AHP and BoD model has been also validated through qualitative interviews with nine persons (three each from board, middle-level management and supervisors) in a structured workshop. They have been shown the demonstration of the application of the model through detailed presentation of the model and its application in three productive systems. The participants have been subsequently asked the on adoptability, usefulness, pros and cons, etc. All the participants conveyed positive remarks on the adoption of the model and presented their positive strategic benefits achieved in long-term organization goal.

The present work can be extended in several ways. The couple of scopes is introduced here. The stakeholders' requirements could be derived from issues and challenges of each process. This will add an additional house of quality that links processes with issues and challenges just before the proposed HoQ-1 as introduced in this study. Instead of the AHP, one can use the analytic network process (ANP) that will allow accommodating the relationship among the criteria. The fuzzy theory will facilitate to consider ranges of outcomes for each alternative. Additionally, combination of these tools and comparison among them might produce interesting perspectives that can help a few users to select their models more objectively. The analysis of causal relationship of organizational productivity and maintenance technique selection using structure equation modelling (SEM) could be another area one could be interested to reveal. According to authors' knowledge, there is very little work in this direction.

Acknowledgments The authors gratefully acknowledge the support of the UKIERI project at Jadavpur University, India and Aston University, UK (UKIERI) (UKUTP201100145).

Open Access This article is distributed under the terms of the Creative Commons Attribution 4.0 International License (http:// creativecommons.org/licenses/by/4.0/), which permits unrestricted use, distribution, and reproduction in any medium, provided you give appropriate credit to the original author(s) and the source, provide a link to the Creative Commons license, and indicate if changes were made.

\section{References}

1. de Smidt-Destombes KS, van der Heijden MC, van Harten A (2004) On the availability of a k-out-of-N system given limited spares and repair capacity under a condition based maintenance strategy. Reliab Eng Syst Saf 83:287-300

2. Van Horenbeek A, Pintelon L (2014) Development of a maintenance performance measurement framework-using the analytic network process (ANP) for maintenance performance indicator selection. Omega 42:33-46

3. Crespo Marquez A, Gupta JN (2006) Contemporary maintenance management: process, framework and supporting pillars. Omega 34:313-326

4. Muchiri P, Pintelon L, Gelders L, Martin H (2011) Development of maintenance function performance measurement framework and indicators. Int J Prod Econ 131:295-302

5. Kutucuoglu KY, Hamali J, Irani Z, Sharp JM (2001) A framework for managing maintenance using performance measurement systems. Int J Oper Prod Manag 21:173-195

6. Shen Q, Lo K-K, Wang Q (1998) Priority setting in maintenance management: a modified multi-attribute approach using analytic hierarchy process. Constr Manag Econ 16:693-702 
7. Tsang AH (2002) Strategic dimensions of maintenance management. J Qual Maint Eng 8:7-39

8. Murthy DNP, Atrens A, Eccleston JA (2002) Strategic maintenance management. J Qual Maint Eng 8:287-305

9. Luce S (1999) Choice criteria in conditional preventive maintenance. Mech Syst Signal Process 13:163-168

10. Parida A, Chattopadhyay G (2007) Development of a multi-criteria hierarchical framework for maintenance performance measurement (MPM). J Qual Maint Eng 13:241-258

11. Arunraj NS, Maiti J (2010) Risk-based maintenance policy selection using AHP and goal programming. Saf Sci 48:238-247

12. Tan Z, Li J, Wu Z et al (2011) An evaluation of maintenance strategy using risk based inspection. Saf Sci 49:852-860

13. Bertolini M, Bevilacqua M (2006) A combined goal programming-AHP approach to maintenance selection problem. Reliab Eng Syst Saf 91:839-848

14. Bashiri M, Badri H, Hejazi TH (2011) Selecting optimum maintenance strategy by fuzzy interactive linear assignment method. Appl Math Model 35:152-164

15. Katchasuwanmanee K, Bateman R, Cheng K (2016) Development of the Energy-smart Production Management system (e-ProMan): a big data driven approach, analysis and optimisation. Proc Inst Mech Eng Part B J Eng Manuf 230:972-978

16. Dey PK (2004) Decision support system for inspection and maintenance: a case study of oil pipelines. IEEE Trans Eng Manag 51: $47-56$

17. Carnero MC (2005) Selection of diagnostic techniques and instrumentation in a predictive maintenance program. A case study. Decis Support Syst 38:539-555

18. Baidya R, Ghosh SK (2015) Model for a predictive maintenance system effectiveness using the analytical hierarchy process as analytical tool. IFAC-Pap 48:1463-1468

19. Chemweno P, Pintelon L, Van Horenbeek A, Muchiri P (2015) Development of a risk assessment selection methodology for asset maintenance decision making: An analytic network process (ANP) approach. Int J Prod Econ 170:663-676

20. Wang L, Chu J, Wu J (2007) Selection of optimum maintenance strategies based on a fuzzy analytic hierarchy process. Int J Prod Econ 107:151-163

21. Chan L-K, M-L W (2002) Quality function deployment: a literature review. Eur J Oper Res 143:463-497

22. Bhattacharya A, Sarkar B, Mukherjee SK (2005) Integrating AHP with QFD for robot selection under requirement perspective. Int $\mathrm{J}$ Prod Res 43:3671-3685

23. Chuang P-T (2001) Combining the analytic hierarchy process and quality function deployment for a location decision from a requirement perspective. Int J Adv Manuf Technol 18:842-849

24. Hanumaiah N, Ravi B, Mukherjee NP (2006) Rapid hard tooling process selection using QFD-AHP methodology. J Manuf Technol Manag 17:332-350

25. Ho W, He T, Lee CKM, Emrouznejad A (2012) Strategic logistics outsourcing: an integrated QFD and fuzzy AHP approach. Expert Syst Appl 39:10841-10850

26. Dey PK, Bhattacharya A, Ho W (2015) Strategic supplier performance evaluation: A case-based action research of a UK manufacturing organisation. Int J Prod Econ 166:192-214

27. Houser JR, Clausing D (1988) The house of quality. Harv Bus Rev 66:63-73

28. Bicheno J (1994) The quality 50: a guide to gurus, tools, wastes, techniques and systems, PICSIE Books, Buckingham
29. Saaty TL (2008) Decision making with the analytic hierarchy process. Int J Serv Sci 1:83-98

30. Thanassoulis E (2000) The use of data envelopment analysis in the regulation of UK water utilities: water distribution. Eur J Oper Res 126:436-453

31. Evans JR, Lindsay WM (2002) The management and control of quality. Cincinnati, OH, South-Western, Vol. 5, pp. 115-128

32. Sullivan LP (1986) Quality progress. June, 12-15

33. Zaim S, Turkyilmaz A, Acar MF et al (2012) Maintenance strategy selection using AHP and ANP algorithms: a case study. J Qual Maint Eng 18:16-29

34. Tsang AH (1998) A strategic approach to managing maintenance performance. J Qual Maint Eng 4:87-94

35. Hameed Z, Hong YS, Cho YM et al (2009) Condition monitoring and fault detection of wind turbines and related algorithms: a review. Renew Sust Energ Rev 13:1-39

36. Caselitz P, Giebhardt J (June 2003) Fault prediction techniques for offshore wind farm maintenance and repair strategies. In: Proceedings of the EWEC2003; Madrid (Spain)

37. Sun Q, Tang Y (2002) Singularity analysis using continuous wavelet transform for bearing fault diagnosis. Mech Syst Signal Process 16:1025-1041

38. Peter WT, Peng YH, Yam R (2001) Wavelet analysis and envelope detection for rolling element bearing fault diagnosis - their effectiveness and flexibilities. J Vib Acoust 123:303-310

39. Tandon N, Nakra BC (1990) Defect detection in rolling element bearings by acoustic emission method. J Acoust Emiss 9:25-28

40. Tan CC (1990) Application of acoustic emission to the detection of bearing failures. In: Int. Tribol. Conf. 1990 Brisb. 2-5 Dec. 1990 Putt. Tribol. Work Reliab. Maintainab. Lubr. Wear Technol. Prepr. Pap. Institution of Engineers, Australia, p 110

41. Leske S, Kitaljevich D (2006) Managing gearbox failure, Dewek. Dewi Magazine; N, 29

42. Butler DE (1973) The shock-pulse method for the detection of damaged rolling bearings. Non-Destr Test 6:92-95

43. Tandon N, Nakra BC (1992) Comparison of vibration and acoustic measurement techniques for the condition monitoring of rolling element bearings. Tribol Int 25:205-212

44. Muller H, Poller M, Basteck A, et al (2006) Grid compatibility of variable speed wind turbines with directly coupled synchronous generator and hydro-dynamically controlled gearbox. In: Sixth Int. Workshop Large-Scale Integr. Wind Power Transm. Netw. Offshore Wind Farms. pp 307-315

45. Zaher AS, McArthur SDJ (2007) A multi-agent fault detection system for wind turbine defect recognition and diagnosis. In: Power Tech 2007 I.E. Lausanne. IEEE, pp 22-27

46. Sorensen BF, Lading L, Sendrup P, McGugan M, Debel CP, Kristensen OJD, et al (2002) Fundamentals for remote structural health monitoring of wind turbines blades - A Preproject. Riso-R1336(EN)

47. Vidoli F, Mazziotta C (2013) Robust weighted composite indicators by means of frontier methods with an application to European infrastructure endowment. Italian journal of applied statistics 23(2): 259-282

48. Garcia MC, Sanz-Bobi MA, del Pico J (2006) SIMAP: intelligent system for predictive maintenance: application to the health condition monitoring of a windturbine gearbox. Comput Ind 57:552-568 